\title{
UMA NOVA ESPÉCIE DE CYRTONEURINA GIGLIO-TOS DO BRASIL. (DIPTERA, MUSCIDAE)
}

\author{
Marcia Souto Couri ${ }^{1}$
}

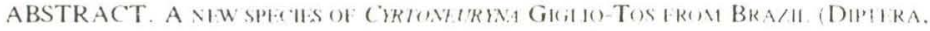

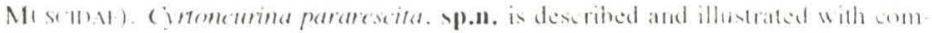
ments on mophological similarities with ongenerie sectes.

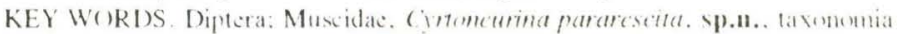

Cyotonearina pararescita. sp.n. foi encontrada em material enviado para identificação pelo Dr. Carlos A.H. Flechtmann (Unirersidade Estadual Paulista Julio de Mesquita Filho, Campus de Ilha Solteira. Säo Paulo). A ohtençào dos adultes se fez a partir de larvas coletadas em tézes de hovino da raça Giuzerá em Selvíria, Mato Grosso do Sul.

\section{Cyrtoneurina pararescita, sp.n.}

Figs $1-10$

Holótipo matho. Br-MS-Selvíria [Brasil. Mato Grosso do Sul|/ UNESP's farm/Ex Guzerá cattle drop/ping-Bracniaria a/cumaens pasture/LIMA, A.C. COL/22/1/1994 [manuscrito]. Pupário no mesmo alfinete do adulto. ambes em montagem dupla (Musea Nacional do Rio de laneiro - MNRJ). Em hom estado, tarso da perna anterior esquerda e perna posterior esquerda quetrades, segmentos terminais do ahdomen e terminália acondicionados em tuhinho de vidro com glicerina.

Parátipo fêmea. Mesmo rótulo do holótipo. Metade anterior do pupário no mesmo alfinete do adulto, ambos em montagem dupla (MNRJ). Em bom estado, tarso da perna média esquerda quebrado, abdomen, terminália e metade posterior do pupário acondicionados em tuhinho de vidro com glicerina.

Reconhecimento. Prosteno nu, cerda pré-alar desenwolvidat, cercas de !/3 docomprimento da primeira supra-alar, fêmea com um par de cerdas inter-frontais cruzadas, anepisterno com três cólios ahaixo da cerda notopleural anterior. Asa hialina, com uma mancha castanha no ápice da R I e em volta das velas transversatis r-me m-m, esta última muito fraca. Rl na face ventral com cílios no $1 / 4$ apical. Pernas castanho-escuras. Tíhia posterior nas faces àntero-dorsal, antero-sentrale póstero-ventral com uma curta cerda mediana. Terminália feminina com cereos curtos e arredondados. com microtríguias, segmento VIII curvo. com espinhose

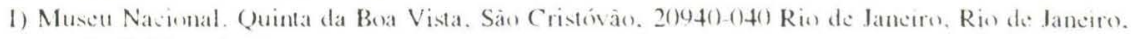
Brasil. Buisista de CNPy. 
mic rotríquias e com oito espinhos desenvolvidos no ápice. Terminália masculina com edeago com espinhos em entumescimento mediano.

Coloração. Castanho-escura. Frontália, parafrontália, faciália e lúnula castanhas com polinosidade prateada. Antena com terceiro artículo castanho com polinosidade cinza, amarelo na hase e segundo artículo amarelo na metade apical. Pré-escuto com quatro listras castanhas e escuto com três, a mediana ating̨indo a hase do escrutelo. Pós-pronoto e escutelo da mesma cor yue o mesonoto. Calíptras hialinas. Halter amarelo. Espiráculo posterior castanho. Asa hialina. eom uma mancha castanha no ápice da Rl e em volta das veias transversais r-m e m-m. esta última muito fraca. Pernas castanho-escuras com articulações fêmoro-tibiais amarelas. Abdômen com manchas castanhas laterais nos tergitos.

Descrição. Macho. Comprimento: 4,6mm; asa: $6 \mathrm{~mm}$.

Caheça. Olhos nus, afastados por um espaço 4,4 vezes menor que a larģura da caheça, no nível do ocelo anterior. Facetas ântero-internas um pouco maiores que as demais. Cerdas frontais em número de nove pares, o último voltado para trás. Antena inserida pouco ahaixo da metade dos olhos, com terceiro artículo medindo cercade 3,4 vezes o comprimento do segundo. Arista plumosa, com cerca de 11 cílios. Vibrissa forte acompanhada de duas sub-vibrissais fortes. Palpo levemente espatulado no ápice.

Tórax. Cerdas acrosticais 0: 1 . Cerdas dorso-centrais $2+4$, os dois primeiros pares pós-suturais semelhantes entre si e cerca da metade do comprimento do terceiro par, quarto par cerca de 1,8 vezes o comprimento do terceiro. Duas cerdas umerais, a externa cerca do dobro da interna; uma pós-umeral, uma pré-sutural longa. Cerda pré-alar desenvolvida, cerca de 1/3 do comprimento da primeira supra-alar, duas supra-alares, a anterior mais longa, duas pós-supra-alares, a posterior o dohro da anterior, cerda intra pós-alar ausente. Notopleura com duas cerdas semelhantes entre si. Escutelo com um par de cerdas hasais e um de apicais. ambos longos, dois pares de laterais, cerca da metade do comprimento dos demais. Prosterno nu. Anepisterno com três cílios longos ahaixo da cerda notopleural anterior e bordo posterior com uma série de 6 cerdas fortes. Cerdas catepisternais $1: 2$. Caliptra inferior medindo cerca de 2,3 vezes a posterior. RI com cílios na face dorsal, desde a transversa umeral até quase o ápice, face ventral com cilios no quarto apical. M $1+2$ com cílios nas duas faces, próximos ao nódulo. Fêmur anterior nas faces póstero-ventral, póstero-dorsal e posterior com uma série de cerdas. Tihia nas faces ântero-dorsal e póstero-dorsal com uma cerda pré-apical. face ântero-ventral com uma cerda apical. Tarso com primeiro segmento longo, com comprimento semelhante à soma dos demais tarsômeros. Unhas e pulvilos pequenos. Fêmur médio na face ântero-ventral com uma série de cerdas curtas, mais curtas na metade apical; face póstero-ventral com uma série de cerdas, as da metade basal mais desenvolvidas; face posterior com duas cerdas pré-apicais semelhantes entre si. Tíhia na face posterior com uma cerda no terço médio e uma subapical: faces ântero-ventral, póstero-ventral e posterior com uma cerda apical. Tarsomeros, unhas e pulvilos como no primeiro par de pernas. Fêmur posterior nas faces ântero-ventral e ântero-dorsal com uma série completa de cerdas, as do 1/3 apical da face ântero-ventral mais longas e fortes. Tíhia nas faces ântero- 
ventral, ântero-dorsal e póstero-dorsal com uma cerca mediana; face pósterodorsal com uma série de cerdas curtas no terço apical; faces ântero-dorsal e ventral com uma cerda apical. Tarso, unhas e pulvilos como nos outros pares.

Abdômen. Tergitos II-IV com uma série de cerdas marginais. Tergito V com uma série de cerdas discais. Esternito $\mathrm{V}$ com profunda incisão posterior (Fig. 1).
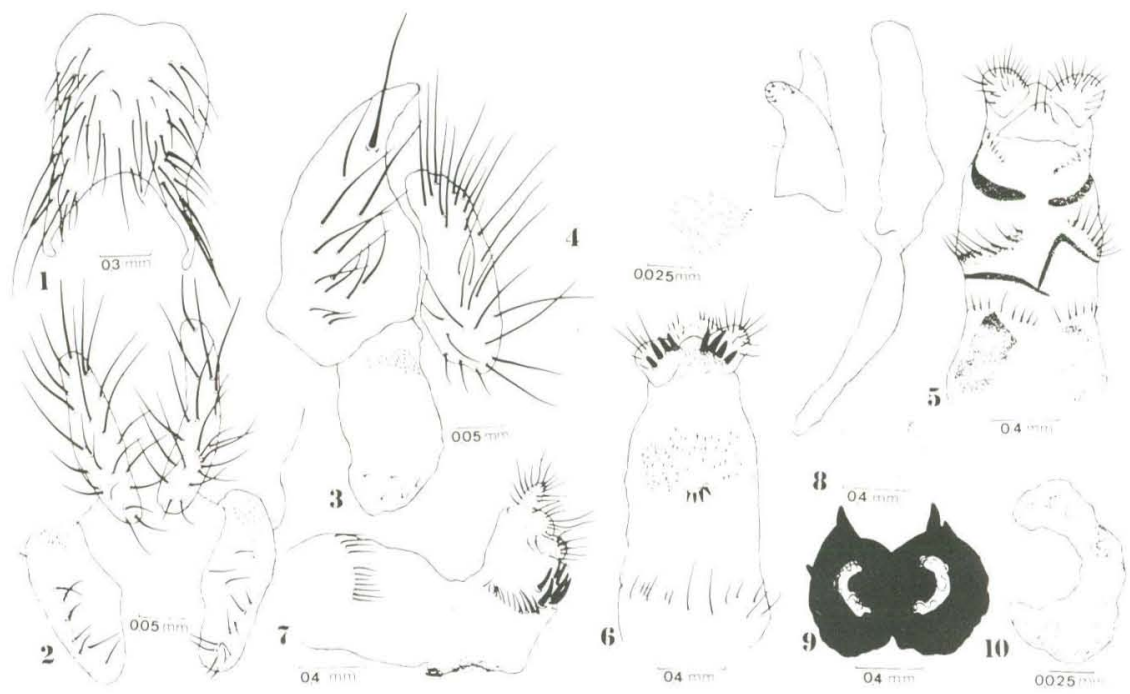

Figs 1-10. Cyrtoneurina pararescita, sp.n. (1) Quinto tergito, macho; (2) placa cercal e sustilos, vista dorsal; (3) placa cercal e sustilos, vista lateral; (4) edeago, vista lateral; (5) ovipositor, vista dorsal; (6) ovipositor, vista ventral; (7) ovipositor, vista lateral. (8) espermatecas; (9) espiráculos posteriores, pupário; (10) fendas espiraculares posteriores, pupário.

Terminália. Placa cercal estreita, sustilos alongados (Figs 2-3). Edeago com espinhos em entumescimento mediano; parâmero com cílios no ápice (Fig. 4).

Fêmea. Similar ao macho, diferindo no que segue: espaço interocular, no nível do ocelo anterior, cerca de $1 / 3$ da largura da cabeça. Cerdas interfrontais cruzadas presentes. Cerdas frontais em número de oito pares.

Terminália. Ovipositor de tamanho mediano, cercos curtos e arredondados e com microtríquias, hipoprocto e epiprocto curtos, segmento VIII curvo, com espinhos e microtríquias e com oito espinhos desenvolvidos no ápice (Figs 5-7). Espermatecas piriformes, em número de três (Fig. 8).

Pupário: Castanho médio, extremidade distal convexa. Espiráculos posteriores fortemente aproximados e com dois processos espinhosos (Fig. 9). Fendas espiraculares sinuosas (Fig. 10).

Etimologia. O nome específico se refere à semelhança morfológica da espécie descrita com C. rescita. 
Discussão. C. pararescita é morfologicamente muito semelhante a $C$. rescita Walker, 1860 , diferindo principalmente pela coloraçäo das pernas e pela terminália feminina. SNydER (1954: 431) faz o seguinte comentário sobre as espécies deste gênero: "Some closely allied species which exhihit striking chaetotaxic differences have remarkably similar genitalia, while certain species which are separahle only on slight color differences exhihit distinct differences in the female terminalia (e.g., wulpi. Fig. 14: polytigma. Fig. 16: and incosnita. F1g. 17)". Este autor examinou 250 espécimens de C. rescita de ambos os sexos. além de algum material-tipo. Provavelmente nem todas as fêmeas foram disisecadas e é possível que hạja mais de uma espécie no material por ele observado. As fêmas dissecadas de C. rescita da Coleção de Diptera do MNRJ apresentam ovipositor como a figrura 12 de SNYDER (op. (it) para esta espécie. As terminálias masculinas de C. rescita, C. wulpie C. pararescita são hastante semelhantes.

AGRADECIMENToS. Ao Dr. Carlos A. H. Flechtmann (Universidade Estadual Patulista Julio de Mesquita Filho, Campus de Ilha Solteira. Sáo Paulo). pela oportunidade de estudar este matcrial.

\section{REFERÊNCIAS}

SNYDER. F. M. 1954. A revison of Ciromeurina Giglio-Tos, with notes on related genera (Diptera, Muscidae). Bull. Amer. Mus. Nat. Hist. $103(6)$ : 421-461. 